\title{
Problematizando o paradigma médico-biologicista na educação: articulações entre educação, saúde e direitos humanos
}

\author{
Cristina Miyuki Hashizume*
}

\section{Resumo}

A presente pesquisa problematiza as consequências da medicalização na educação a partir de uma reflexão sobre o uso de psicofármacos no controle de comportamentos considerados inadequados para o aprendizado escolar. A partir dessas consequências, refletiremos a respeito dos desdobramentos na saúde pública e no debate acerca dos direitos humanos. Em estudo realizado (HASHIZUME, CARDOSO, LIMA, 2018), discutimos os desafios da formação docente para modificar o uso excessivo de psicofármacos em diagnósticos errôneos que tratam comportamentos inadequados como transtornos. O objetivo deste artigo é discutir o papel do professor na garantia de práticas escolares diferenciadas que revertam os problemas de aprendizagem e estejam em acordo com a valorização e respeito aos direitos humanos dos alunos. $\mathrm{O}$ método utilizado no presente artigo foi bibliográfico, pela análise de documentos e estado da arte sobre o tema. Utilizamos o método qualitativo com análises da legislação existente acerca do tema, além de publicações realizadas por pesquisadores engajados no movimento do Fórum de Medicalização da Vida e da Sociedade. A análise bibliográfica se fundamentou em trabalhos, teses, artigos dos seguintes autores: Collares e Moysés (2013); Hashizume e Dietrich (2017); Viègas (2014). A pesquisa possibilitou adentrarmos em uma temática promissora e de suma importância para a atualidade, tendo em vista sua parca discussão na educação. Entendemos que o educador pode auxiliar nessa nova realidade, sendo protagonista e mediador na construção de uma cultura da paz.

Palavras-chave: Educação. Direitos Humanos. Medicalização.

* Doutora em Psicologia pela USP. Professora do Programa de Mestrado em Educação da UMESP e do Programa de Psicologia Educacional do UNIFIEO. cristina.hashizume@metodista.br 


\section{The problem of the medical-biological paradigm in education: links between education, health and human rights}

\section{Abstract}

The present research deals with the consequences of medicalization in education based on a reflection on the use of psychotropic drugs in the control of behaviors considered unsuitable for school learning. From these consequences, we will reflect on developments in public health and the studies about Human Rights. In another study (CARDOSO, LIMA, HASHIZUME, 2018), we discuss the challenges of teacher training to modify the excessive use of psychotropic drugs in wrong diagnoses that treat inappropriate behaviors as disorders. This article aims to discuss the role of the teacher in guaranteeing differentiated school practices that are in accordance with the appreciation for student's human rights. From the readings made, we believe that the teacher has a decisive role in solving learning problems using pedagogical methods, not medication. The method used in this article was bibliographical studies and documents. We used the qualitative method through readings and analyzes of existing legislation on the subject, as well as publications made by researchers engaged in the movement of the Forum of Medicalization of Life and Society. The bibliographic analysis was based on thesis works, articles of the following authors: Collares e Moysés (2013); Hashizume and Dietrich (2017); Viègas (2014). The research made it possible to enter into a new theme and of great importance for the present and that there are still few authors who discuss this subject in Pedagogy. We understand that the educator can help in this new views about it, being protagonist and mediator in the building of a culture of peace.

Keywords: Education. Human rights. Medicalization.

\section{El problema del paradigma médico-biológico en la educación: vínculos entre educación, salud y derechos humanos.}

\section{Resumen}

Esta investigación analiza las consecuencias de la medicalización en la educación a partir de una reflexión sobre el uso de drogas psicotrópicas para controlar comportamientos considerados inapropiados para el apren- 
dizaje escolar. A partir de estas consecuencias, reflexionaremos sobre la evolución de la salud pública y el debate sobre los derechos humanos. En otro estudio (HASHIZUME, CARDOSO, LIMA, 2018), discutimos los desafíos de la educación docente para modificar el uso excesivo de drogas psicotrópicas en diagnósticos erróneos que tratan los comportamientos inapropiados como trastornos. El propósito de este artículo es discutir el papel del maestro en asegurar prácticas escolares diferenciadas que estén de acuerdo con los derechos humanos de los estudiantes. El método utilizado en este artículo fue bibliográfico a través del análisis de documentos y el estado del arte sobre el tema. Utilizamos el método cualitativo mediante el análisis de la legislación existente sobre el tema, así como las publicaciones de investigadores involucrados en el movimiento del Foro de Medicalización de la Vida y la Sociedad. El análisis bibliográfico se basó en tesis, artículos de los siguientes autores: Collares y Moysés (2013); Hashizume y Dietrich (2017); Viègas (2014). La investigación nos permitió entrar en un tema prometedor de gran importancia para el presente, dada su limitada discusión en educación. Entendemos que el educador puede ayudar en esta nueva realidad, siendo protagonista y mediador en la construcción de una cultura de paz.

Palabras clave: Educación. Derechos humanos. Medicalización.

\section{Introdução}

Este artigo apresenta um estudo introdutório sobre o uso de medicamentos (psicofármacos) no controle de comportamentos considerados como inadequados para o aprendizado escolar. Tal realidade tem sido debatida, analisada e mapeada em estudos de vanguarda acerca do tema, desde os anos 2000. A partir da consequência de tal uso, refletiremos a respeito dos seus rebatimentos na saúde pública e no debate sobre direitos humanos. ${ }^{1}$

Em outro estudo realizado (CARDOSO, LIMA, HASHIZUME, 2018; HASHIZUME, SANTOS, 2019), discutimos os desafios da formação docente para modificar o uso excessivo de medicamentos no tratamento de comportamentos inadequados, diagnosticados como transtornos.

1 Tais estudos têm sido desenvolvidos em Trabalhos de Conclusão de curso, na Pedagogia, nos anos de 2018 e 2019. 
O objetivo deste artigo é problematizar as relações entre saúde e educação, propondo um entendimento colaborativo entre as duas áreas, no sentido de perceber o aluno como ser humano integral, que tem o direito a acesso à educação, sendo necessário tolerância do professor em relação às suas especificidades no processo de aprendizado. O que temos percebido é que a docência tem lançado mão do discurso e práticas médicas e farmacológicas, buscando situar no corpo (biológico) evidências inegáveis sobre a causalidade de problemas mentais e de aprendizagem (CALIMAN, 2013). Soma-se a esse cenário uma grande preocupação em relação à produtividade desse aluno, que precisa manter notas e um ritmo de aprendizagem minimamente médio, mensurado e comparado ao restante da turma. Também pretendemos discutir o papel do professor na garantia de práticas escolares diferenciadas, que colaborem nos problemas de aprendizagem, de acordo com a valorização e respeito aos direitos humanos dos alunos, acreditando que, dessa forma, se garantiria a formação de novas gerações para a cultura da paz. A bibliografia aqui utilizada foi analisada durante disciplinas na pós-graduação abordando direitos humanos e cultura da paz.

Este trabalho será dividido em três partes. Num primeiro momento, apresentaremos o acesso à educação como um direito humano, rechaçando práticas de exclusão escolar por meio de procedimentos de cunho higienistas, que não aceitam/incluem todos os alunos em suas diferentes formas de aprendizagem (ZUCOLOTTO, 2007; CALIMAN, 2013; MACHADO, 1996; PATTO, 1999; SCHWARCZ, 1993). A seguir, abordaremos o fenômeno da medicalização dos problemas de aprendizagem, discussão iniciada no início dos anos 2000, tendo seu ponto alto nos anos 2012, e que vem sendo agregada a novas atualizações, referenciais teóricos e métodos de estudos, não só em Psicologia Educacional, mas também de áreas aderentes, e também, na saúde pública.

E por fim, o artigo propõe uma visão sobre a medicalização que articula saúde e educação como práticas necessárias para o docente propiciar, com os alunos, com as políticas públicas e as práti- 
cas de gestão, uma aprendizagem mais significativa e efetivamente garantidora de direitos, grande desafio para a atual conformação de nossa sociedade brasileira.

\section{Introduzindo o tema}

Importantes cidades no Brasil vêm discutindo o tema e seus impactos no cotidiano da escola no que se refere à medicalização dos problemas de aprendizagem. O munícipio de São Paulo tem a lei número 986, de 2014. No Rio de Janeiro, a Resolução nº 177, de 11 de dezembro de 2015 "dispõe sobre o direito da criança e do adolescente de não serem submetidos à excessiva medicalização" (CONANDA, 2015, p. 1). Na Prefeitura de Campinas-SP, há um protocolo de uso de Metilfenidato, droga mais utilizada por crianças diagnosticadas com TDAH.

No entendimento de agências internacionais de saúde e do poder público brasileiro, conforme exemplificado em algumas prefeituras mais engajadas com o tema, o uso do medicamente pressupõe uma visão de corpo apenas material e biológico, que desqualifica diagnósticos que levem em consideração contextos, relações sociais, especificidades construídas ao longo da história do indivíduo. Nesse sentido, a partir desse paradigma, diagnósticos contextualizados e interdisciplinares, que incluam olhares de professores, pais, assistentes sociais dificilmente têm a mesma legitimidade do que o discurso médico biologicista, mesmo que o objeto de estudo seja eminentemente um fenômeno da relação, da mediação entre professor e aluno.

Apesar dessas questões, por um lado, organismos internacionais e estudiosos de áreas correlatas à educação e psicologia educacional entendem que o medicamento deve ser visto como "adjuvante no estabelecimento do equilíbrio comportamental do indivíduo, aliado a outras medidas, como educacionais, sociais e psicológicas" (SMS, 2015, p. 5), e não um fim em si para a sanidade das crianças acometidas por esses transtornos. Como agentes públicos e estudiosos sobre os problemas de aprendizagem, por outro lado, o sistema 
educacional tem potencialidade para auxiliar no conhecimento e esclarecimento da sociedade para que a criança não se resuma a uma "subjetividade-diagnóstico", em que a criança passa a ser vista como "a" autista, "a" hiperativa, "a" sindrômica, sem que seu modo particular seja considerado como importante na história de aprendizagem. Entendemos que a aprendizagem segue um ciclo vital, que acompanha um funcionamento holístico que apresenta características geracionais e contextuais das crianças nas escolas. Trata-se, portanto, de se construir um olhar cuja mentalidade valorize e respeite o funcionamento diferente, mesmo que não previsto, tradicionalmente, nas escolas: um tratamento aos problemas de aprendizagem que fuja à lógica biologicizante. Somos mais do que corpos físicos, mais do que os diagnósticos que querem nos imputar para minimizar o julgamento moral sobre os comportamentos apresentados.

Do mesmo modo, vale ressaltar a formação dos professores como prática necessária para a revalorização do trabalho docente que potencializa a ação e pode reverter dificuldades na lida cotidiana escolar. A capacitação do docente possibilita que este consiga valorizar seu conhecimento a ponto de oferecer estratégias pedagógicas que efetivamente modifiquem as problemáticas levantadas pelos docentes, e que têm sido resolvidas atualmente apenas por especialidades médicas.

\section{Direitos humanos e a medicalização}

Iniciados com a Declaração Universal dos Direitos do Homem, em 1948, os Direitos Humanos, na atualidade, têm várias conceituações. Porém, em nosso entendimento, é muito mais do que um novo especialismo a ser estudado, ou seja, uma nova área que gera volumes e mais volumes de publicações, tratamentos, especialistas, e toda uma indústria produtiva que subjaz a essa nova forma de lidar com os problemas cotidianos da vida, sejam eles na saúde, na educação, e em outras esferas da nossa vida privada ou pública. Para que possamos discutir direitos humanos e educação, em primeiro lugar, faz-se necessário diferenciar a visão que o sen- 
so comum tem, ancorada no que é publicizado pela mídia aberta. A partir de tal visão, constrói-se um modo de pensar simplificado que criminaliza os movimentos que defendem os direitos humanos para todos. Frente a essa visão, faz-se necessário reforçarmos, junto aos espaços de formação, como a universidade, o real sentido dos Direitos Humanos, que deve assegurar, a qualquer cidadão, seja ele com deficiência, ou pertencente a quaisquer raças/etnias, de quaisquer classes sociais, o direito ao acesso à educação.

Comparato (2018) traz à discussão o debate entre filosofia e a epistemologia dos Direitos Humanos, defendendo que para entendermos os Direitos Humanos é necessária a compreensão de definições básicas que são as chaves para a crítica dos direitos. Para tanto, o autor discute o conceito de justiça, perpassando por discussões sobre ética e participação social, a partir da reflexão da lógica da justiça e não justiça coletiva. Piovesan discute os Direitos Humanos a partir da militância. Em "Temas de Direitos Humanos", faz um histórico dos Direitos Humanos desde a Revolução Francesa até os debates atuais de políticas afirmativas, passando pela Declaração dos Direitos Humanos de 1948. Piovesan (2004) e seus escritos nos permitem compreender que os Direitos Humanos devem ser universais, indivisíveis, garantidores da exigibilidade e justiciabilidade, além da igualdade de condição e liberdade de acesso a eles por meio do pluralismo de ideias.

Em um projeto importante sobre Educação e Direitos humanos (HASHIZUME \& DIETRICH, 2017), discutimos o tema a partir de projetos realizados in loco nas escolas, com o objetivo de se formar docentes e alunos para a cultura da paz, conforme o previsto nos Parâmetros Curriculares Nacionais e na LDB. Como um tema transversal, os Direitos Humanos não são apenas disciplinas, mas se trata de uma formação que perpassa outras instâncias, como o emocional, social, espiritual, por exemplo. Nesse sentido, a educação deve se debruçar sobre este premente desafio: como problematizar tais questões de modo a trazer o aluno para o protagonismo em relação aos Direitos Humanos? Como fazê-lo dialo- 
gar e discutir sobre as questões da realidade não apenas individual, mas coletivamente, mediando a relação entre cidadão, instituições e Estado? Instrumentalizar o cidadão e o professor com noções de Direitos Humanos desenvolve no indivíduo o seu pertencimento, autoestima e cidadania. Empoderar esse sujeito a partir de conhecimentos e discussões faz que as pessoas partilhem de um senso coletivo de justiça, colaborando para organizar moções, petições populares, documentos direcionados ao Ministério Público, pensando na justiça social coletiva e não apenas em si próprio. Trata-se de um grande desafio da atualidade, pois nossa sociedade forma as novas gerações para o consumo, competição e individualismo, o que é muito preocupante para nós, formadores. Como formadores, nossa diretriz deve ser promover uma identificação do aluno com os direitos e deveres num debate, uma vez que os tutores mediarão sua formação, debater a cultura de paz, por meio de debates de situações concretas e cotidianas.

De modo diferente do que se apregoa, lutar pelos Direitos Humanos, e especificamente pelo direito a ter acesso à educação, é mais do que se vitimizar, mas é reconhecer a sua consciência enquanto sujeito de direitos e deveres que todo cidadão deve ser, recuperando a sua autoestima (NEVES, 2010). Nesse sentido, alunos e alunas negros, com deficiência, com diferentes diagnósticos não devem ser vistos como vítimas e inaptos, mas sim, sujeitos que merecem a equidade como tratamento e reconhecimento de acesso digno à educação, aos conteúdos dados na escola regular, às oportunidades de estudo e de ilustração.

Ideologias diversas podem ser tão nocivas e violentas como a agressão física ou verbal. Quando tomados por ideologias intolerantes, que não reconhecem o outro como um ser humano, podemos ter ações destrutivas em relação àqueles que não pensam ou se comportam como a média da população. Nesse aspecto, a ideologia, aliada à intolerância, pode se tornar uma grande arma contra a garantia dos direitos aos alunos com deficiência. Pelo preconceito e bullying que podem gerar em relação ao diferente - não tolerado. 
Que aluno "mais agitado", ou "considerado hiperativo" vai querer ser alvo de práticas intolerantes? Frente a essa questão, abrem-se brechas para o uso de procedimentos médicos para "sanar" a diferença que destoa da média. Relações ético-raciais, culturais, de gênero, acabam sendo tratadas como questões biológicas, corporais, que precisam ser constatadas via exames de imagem e rapidamente redirecionadas ao funcionamento "normal" (INSFRAN, 2017).

Os direitos humanos consistem em que todos tenham direitos específicos a ser respeitados, independentemente de raça, sexo, nacionalidade, etnia, idioma, religião ou qualquer tipo de condição. Por todas as pessoas nascerem livres e iguais em dignidade e direitos e serem dotadas de razão e consciência, devendo agir em relação umas às outras com espírito de fraternidade, gozando dos direitos e liberdades estabelecidos na Declaração, sem distinção de qualquer espécie (raça, cor, sexo, língua, religião, opinião política ou outra condição (CASTILHO, 2011, p. 11) é que precisamos capacitar alunos e professores.

Alguns desses direitos irrefutáveis são a educação e a saúde: no artigo 26. ${ }^{\circ}$, a Declaração dos Direitos do Homem propõe que todos têm o direito a educação gratuita e que vise o pleno desenvolvimento do indivíduo, e o artigo $25 .^{\circ}$ rege que:

Toda a pessoa tem direito a um nível de vida suficiente para lhe assegurar e à sua família a saúde e o bem-estar, principalmente quanto à alimentação, ao vestuário, ao alojamento, à assistência médica $\mathrm{e}$ ainda quanto aos serviços sociais necessários (UDHR, p. 1).

O artigo 3. ${ }^{\circ}$ do Estatuto da Criança e do Adolescente (BRASIL, 1990) garante direitos fundamentais a toda criança e adolescente: educação, saúde, lazer, entre outros. As condições dignas de existência devem estar resguardadas. Esse excerto da Declaração dos Direitos Humanos aponta para a inter-relação estreita entre os direitos da educação e da saúde, no sentido de que devem ser atendidos totalmente para que o indivíduo consiga minimamente se sentir contemplado em sua dignidade e cidadão de direitos. Formar 
novas gerações com um propósito de serem cidadãos cônscios de seus direitos e deveres requer lhes garantir o respeito pela sua saúde integral, compreendendo o jovem aluno como um ser inteiro. A abordagem na formação, seja de alunos, seja de professores, perpassa o cuidado com a integralidade de todo ser humano, visto que este deve ser praticante de seus direitos e deveres. Nesse sentido, todo futuro cidadão precisa ter seus direitos assegurados, devendo passar por uma formação que envolva a saúde, numa perspectiva mais ampla, de cuidado de si e dos outros.

A Declaração Universal dos Direitos Humanos garante que todas as pessoas tenham o direito à vida e à segurança pessoal, o que, em nosso entendimento, não nos parece atendido nas situações de violência ou de discriminação pelas quais passam crianças com diagnósticos de TDAH e déficit de atenção. Nos estudos levantados, fica nítido que o diagnóstico é realizado por exames clínicos, em alguns casos, de forma apressada e com o posicionamento de um único profissional, em geral, médico:

O Boletim de Farmacoepidemiologia do Sistema Nacional de Gerenciamento de Produtos Controlados (SNGPC) afirma que as estimativas de prevalência de TDAH em crianças e adolescentes bastante discordantes foram encontradas no Brasil, com valores de $0.9 \%$ a $26.8 \%$. Nenhum exame laboratorial confiável prevê esse tipo de problema (SMS, 2015).

"Esse tipo de diagnóstico, bem com o diagnóstico de dislexia e outros transtornos afins, têm sido considerados controversos por inúmeros estudiosos. As dificuldades de escolarização necessitam ser bem fundamentadas, uma vez que estão associadas a conduta medicamentosa psicotrópica com metilfenidato, que além de produzir inúmeros efeitos colaterais objetivos, produz efeitos subjetivos de consequências imensuráveis sobre a autoestima da criança...." (SMS, 2015).

Sendo assim, sua segurança pessoal, dignidade e direito ao seu pleno desenvolvimento são diretamente afetados, pois o uso de medicamentos psicofármacos pressupõe uma culpabilidade individual, genética, e fisiológica, sobre a qual as interações humanas não po- 
dem, segundo esse ponto de vista, modificar/formar o indivíduo, a ponto de ser capaz de se superar e se abrir para outras possibilidades de desenvolvimento. Nesse sentido, entender o comportamento humano na escola como uma marca biológica ou sintoma de uma síndrome ou transtorno é reduzir as possibilidades de transformação e mudança social do aprendente em sua interação pedagógica com o professor. É como um desvio de percurso: frente a uma problemática puramente dialógica, inter-relacional, buscamos um remédio para que o físico, o palpável, nos dê a sensação de absoluto controle sobre os nossos corpos, e por consequência, nossa mente.

Nesse sentido, fica nítido o caráter de biopoder, ou seja, de controle do corpo "anormal". O biopoder, conceito ancorado em constructos teóricos de Foucault (1979), e também especificamente no Resumo dos Cursos do Collège de France (1997), se refere a uma espécie de "anatomo-política" ligada ao treinamento dos corpos voltada para a produção, dentro de um processo de normalização na constituição dos seres vivos, ou seja, um tipo de política (con) formadora da vida e dos sujeitos. Tal conceito procura gerir o viver, maximizando os efeitos do poder disciplinar, fortemente presente nos séculos XVII e XVIII. Na segunda metade do século XVIII, uma nova forma de poder começa a se explicitar. Sem dispensar as técnicas disciplinares, a nova prática de controle elege outros objetos de aplicação: ao invés de atuar em instituições fechadas e nos corpos, a estratégia da biopolítica maximiza os esforços disciplinares por se alastrar pelos espaços abertos, muito além das instituições, e se dirigir ao homem como ser vivo, como espécie humana: o foco agora é a população (TEDESCO \& NASCIMENTO, 2009). O corpo se mantém como matéria do poder, mas como "corpo múltiplo". A população emerge como problema científico e político (FOUCAULT, 1976). E ao problematizar fenômenos populacionais, estabelecem-se generalizações, normalizações e níveis globais de equilíbrio. Nessa nova forma de poder, a ação é no sentido de produzir subjetividades dentro de uma regularidade, buscando a homogeneização por meio de padrões gerais de conduta sociais. 
A biopolítica engloba um conjunto de biopoderes locais, isto é, como uma nova tipologia de relações de poder que se aplicam à vida (FOUCAULT, 1997). Tais modos de poder se alastram, utilizando instituições como a escola, o hospital, além de discursos socialmente legitimados como o do Direito, da Medicina e das Neurociências, que têm como objetivo subjacente o controle do corpo-biológico: por detrás de uma preocupação com o biológico, fisiológico e psicológico, o esquadrinhamento do corpo tem fins de controle (FUGANTI, 1990). No biopoder, se controlam o pensamento, os modos de comportamento, enfim, a vida. Tal visão é engendrada a partir do "consentimento da sociedade, que delega à medicina a tarefa de normatizar, legislar e vigiar a vida" (COLLARES, MOYSÉS, 2008, p. 1). Esse saber legitimado será problematizado em nosso artigo, recuperando o saber artesanal, construído em sala de aula, na interação professor aluno e que é relevante e decisivo na reversão de processos escolares que causam os problemas de aprendizagem.

\section{Relações entre saúde e educação: uma proximida- de necessária}

O excesso nos diagnósticos, assim como o uso indiscriminado de medicação, pode acarretar em novas complicações futuras, que terão que ser cuidadas pelo Sistema Único de Saúde. Além de uma questão de saúde pública, há dilemas éticos envolvidos no uso excessivo de medicamentos, exames e diagnósticos no corpo físico sobre problemas eminentemente sociointeracionistas, haja vista interferência do poder público no sentido de impedir esses excessos (FÓRUM, 2014, p. 3). A saúde tradicionalmente é usada como saber para intervir e controlar os corpos. Isso acontece com o saber médico, das Neurociências, as vacinas, o discurso da prevenção. Esse controle sobre os corpos vem sendo emprestado para os professores como uma forma de biopoder: controle da vida e da subjetividade dos corpos vigiados.

Estudos mostram não termos dados suficientes que demonstrem os problemas que podem afetar o desenvolvimento da 
saúde plena do ser humano, pois "como a medicação costuma ser retirada em torno dos 18 anos, esses jovens podem ser tornar adictos à cocaína na vida adulta, como modo de substituir a droga legal que tomaram por anos" (COLLARES, MOYSÉS, 2013, p. 16). Por afetar todos os aparelhos e sistemas do corpo humano, com destaque para o sistema nervoso central, sistema cardiovascular, e sistema endócrino-metabólico (COLLARES, MOYSÉS, 2013 p. 16), prevemos que, em longo prazo, será alta a possibilidade de adultos adoecidos pelo uso excessivo desses medicamentos, tendo seu prognóstico impactando diretamente a Saúde Pública. Refletimos em como a educação poderia vir a ser um instrumento para abordar essas questões de forma preventiva. O sistema educacional pode ser um protagonista, trazendo à tona essa temática e auxiliando a sociedade a refletir e buscar outras formas de auxílio às crianças com problemas de aprendizagem, antes de inseri-las na via medicamentosa. Dar aos alunos e pais a possibilidade de escolha em relação ao uso de medicamentos é dar-lhes a orientação necessária para que eles sejam poupados de futuras sequelas ainda não imagináveis no aprendizado futuro.

Uma saída que seria efetivamente possível trata-se de construir com a "comunidade escolar uma participação da vida democrática, problematizando os direitos e responsabilidades da sociedade, através de uma educação integral para a construção de uma nova ética inclusiva e mais tolerante com as diferenças" (DIETRICH, HASHIZUME, 2017, p. 131). Do mesmo modo, na sala de aula, os educadores têm contato direto com as diferenças existentes na aprendizagem, enxergam as dificuldades e problemas na educação. Acreditamos que por meio de uma organização educacional que vise abordar essas diferenças com um olhar além das dificuldades, poderíamos modificar essa estrutura que vem se formando ao longo dos anos, de medicalizar nossas crianças e adolescentes que têm modos de aprendizados diferentes da média.

Ao pensar em políticas públicas educacionais coerentes, que levem em consideração o contexto social, cultural, econômico, fa- 
miliar, onde a escola está inserida, é importante pensar na formação e valorização de professores que, por muitas vezes, atuam em mais de uma escola. Ao construir um espaço de formação docente, atuamos na autoestima profissional do professor: existem vários fatores a serem pensados, refletidos, analisados e mudados, para que possamos alcançar uma proposta educacional que não fira os direitos humanos de qualquer ser humano, sejam crianças, adolescentes, jovens, idosos.

O papel do professor, no HTPC, deve ser protagonista e alinhado às políticas públicas educacionais e de saúde, visando a reversão de uma lógica medicalizante e biologicista, que impera no senso comum para se explicar todos e quaisquer fenômenos e problemas na contemporaneidade. Conquista dos trabalhadores da educação, o HTPC (Horário de trabalho pedagógico coletivo) apresenta-se como um importante lócus para problematização de práticas enrijecidas e medicalizadas, que insistem em se repetir no cotidiano escolar. A burocratização dos processos escolares interfere e toma o tempo do docente, que se perde na burocracia, ocupando momentos imprescindíveis para a criação coletiva de novas estratégias para se lidar com as questões que se colocam na escola em relação aos problemas de aprendizagem.

Nesse momento, vale a pena retomar discussões sobre inclusão e estigma, o discurso médico e sua invasão no ambiente pedagógico e docente, o gerencialismo do trabalho docente e sua interferência na gestão escolar e na autonomia docente, a sobrecarga de trabalho e o modo de trabalho produtivista que impera na escola, as cobranças de produção em relação ao trabalho do professor, aluno e gestão, que resumem a qualidade do ensino nas performances nas avaliações externas que são feitas por órgãos que nem sempre consideram as especificidades do contexto escolar que se estuda. Enfim, os desafios para os profissionais da educação são muitos e não devem recair apenas na figura do professor. Este deve estar presente, sim, na escola, produzindo conhecimento, controlando o aprendizado da criança, visando a qualidade de seu conhecimento 
a ser construído. Mas devemos também ter a consciência de outras questões que atravessam a produção do conhecimento e que afetam diretamente a produtividade docente e discente: algumas questões que estão em nível de gestão educacional, e que precisam ser problematizadas pelos trabalhadores da educação em seu protagonismo. Promovendo o controle social, comunidade escolar, professores, técnicos e gestão devem focar o aluno, na aprendizagem, na qualidade da educação. E com o foco nessas questões, lançar mão de diferentes disciplinas e áreas do conhecimento, não para culpabilizar, mas para compreender como os problemas de aprendizagem se engendram e como podemos fazer para desconstruí-los, dentro de uma lógica que seja mais inclusiva, efetivamente.

Numa sociedade em que estão inventando as doenças do "não aprender" (COLLARES, MOYSÉS, 2013, p. 15), a escola tem a oportunidade de auxiliar nessa mudança. Ao formar nas séries iniciais novas gerações de docentes mais sensíveis em relação aos diferentes modos de aprendizado e funcionamento, modifica-se a visão patologizante a respeito dos alunos que fogem à média. É necessário que o sistema escolar - gestores, professores, coordenadores pedagógicos - lance um olhar diferente sobre o uso de psicofármacos nas crianças e que possibilite acesso a informações acerca do uso abusivo a toda a comunidade escolar. Os alunos, nas formas em que vivem a experiência escolar, não devem tanto ser tratados como iguais, mas, sim, reconhecidos nas suas especificidades, seja em seus comportamentos, seja no ritmo da aprendizagem. A escola é demandada por sua clientela para que seja capaz de criar instrumentos que ajudem os alunos a serem capazes de conduzir a própria vida, já que vivemos numa sociedade na qual a construção de si é fundamental para dominar seu destino. De todo modo, os espaços educacionais devem ser compreendidos como múltiplos, ultrapassando os muros das escolas e atingindo outros espaços de referência, como organizações sociais e movimentos sociais. O Movimento da Medicalização, dentro desse cenário, nos demonstra que é no debate coletivo em que se constroem novas formas de 
enfrentar as dificuldades de aprendizagem que surgem na escola; é na escola, lócus privilegiado de debates, que devemos inserir debates coletivos para problematizar o uso de psicofármacos e construir novas estratégias para trabalhar com os alunos que apresentam dificuldades de aprendizagem. Por meio do protagonismo de alunos, docentes, pais e comunidade escolar do entorno é que soluções criativas podem ser construídas com a ajuda dos educadores, de modo a pensar o aprendizado, mas, e também, o bem-estar do futuro cidadão que está em formação. Desse modo, podemos garantir que os Direitos Humanos serão cumpridos na medida que o futuro cidadão acessa a escola e a sua formação.

\section{Considerações finais}

\section{Pensando a saúde e a educação como direitos ne- cessários para a construção da cultura da paz}

Vivemos numa sociedade em que tudo que é diferente, que foge à normalidade, se transformou em doença, em problema biológico e individual. Assim como os problemas de aprendizagem, questões como o sofrimento, o luto, a tristeza e demais sentimentos da vida humana estão sendo abordados em seus aspectos fisiobiológicos, o que remete a um entendimento de natureza como um modo de funcionamento automático e inevitável. A partir do olhar apenas biológico e patologizante, desconsideramos que a vida está inserida num contexto social, político, educacional e cultural, que contraditoriamente influencia o processo de formação humana. Ao desconsiderar esses aspectos, tratamos nossos alunos como se estivessem num laboratório sob condições controladas, colocando-nos numa situação em que corremos o risco de chegarmos a conclusões simplificadas sobre um cenário muito complexo.

Tem sido frequente no campo de atuação educacional comportamentos tidos como anormais serem tratados por profissionais da área da saúde, médicos pediatras, psiquiatras, neurologistas. Há uma insistência em buscar algo de biológico, visível e evidenciado 
da forma mais material possível, dando concretude à anormalidade, que demandará prognósticos tão biológicos e materiais quanto os exames que ajudam a diagnosticar tais patologias. É necessária a implementação de dispositivos de suporte ancorados em uma lógica mais coletiva que envolva a comunidade escolar, com investimento permanente em mecanismos que garantam a efetivação de propostas e programas condizentes com tais pressupostos. Mas para isso, a comunidade deve estar ciente de seus direitos e deveres e ser protagonista nesse processo.

Promover o protagonismo e autonomia aos educandos público-alvo da educação especial e com dificuldades/transtornos de aprendizagem por meio de um projeto pedagógico realmente inclusivo é um desafio para toda a comunidade escolar. O desafio deste projeto transcende as definições citadas sobre o protagonismo, pois requer promover o protagonismo dos atores escolares, dentro da proposta inclusiva, sendo assim, alunos com deficiências, transtorno global do desenvolvimento, altas habilidades/superdotação e com transtornos/dificuldades de aprendizagem e seus pais são incentivados a participar de um processo de ressignificação de si, da sua dificuldade, das políticas públicas que possam estar disponíveis a eles, além de considerá-los protagonistas no controle social.

Trabalhar com saúde e educação é atuar no resgate desse sujeito como aprendente, capaz e potente ação fundamental para construir uma visão saudável e inclusiva sobre o aluno com necessidades especiais. O cuidado com o olhar, agora menos patologizante, também torna mais rigorosa a categorização e o cuidado a esse alunado. A visão do aluno integral é uma visão que respeita o ciclo natural saudável do corpo e da mente, dentro de um entendimento integrativo sobre o ser humano e suas relações com o meio ambiente.

A partir das discussões trazidas neste ensaio, percebemos que a relação entre saúde e educação é muito tênue: formar é ajudar na construção de uma subjetividade do indivíduo, que deve ser protagonista, autônoma, mas para que isso seja possível, é necessário que o paradigma médico não impere sobre os saberes pedagógicos 
como discurso legitimado. É necessário que o professor tenha o seu saber e discursos também reconhecidos na escola, tendo autonomia de buscar saídas dialogadas com outros professores, ou profissionais de outras áreas, porém, este deve reconhecer seu próprio saber como legítimo, importante e necessário para a condução de problemas de aprendizagem de seus alunos. Problematizar a medicalização é um importante passo nesse sentido.

\section{Referências}

BRASIL, Estatuto da Criança e do Adolescente, Brasília, 1990. Disponível em: <http://www.planalto.gov.br/ccivil_03/LEIS/L8069.htm> Acesso em: 11/10/2018.

CALIMAN, L. Os Bio-diagnósticos na era das cidadanias biológicas. In: COLLARES, C. A. L.; MOYSÉS, M. A. A.; RIBEIROS, M. C. F. Novas capturas, antigos diagnósticos na era dos transtornos: memórias do II seminário internacional. Campinas, SP: Mercado de Letras, 2013.

CASTILHO, R. Direitos Humanos. São Paulo, SP: Saraiva, 2011.

COLLARES, C. A. L.; MOYSÉS, M. A. A., Educação ou saúde? Educação X Saúde? Educação e saúde! Cadernos Cedes, n. 15, 1985.

COMPARATO, F. K. Fundamento dos Direitos Humanos. Disponível em: <http://www.dhnet.org.br/direitos/anthist/a_pdf/comparato_fundamentos_dh.pdf> Piovesan. Acesso em: 16 dez. 2018.

FÓRUM SOBRE A MEDICALIZACAO DA EDUCAÇÃO E DA SOCIEDADE. Dossiê sobre medicalização da educação e da sociedade. s.l.: s.d. Disponível em: <http://medicalizacao.org.br/dossie-sobre-medicalizacao-da-educacao-e-dasociedade/> Acesso em: 19/05/2018.

FOUCAULT, M. Microfísica do poder. Rio de Janeiro: Graal, 1979.

Resumo dos Cursos do Collège de France. Rio de Janeiro: J. Zahar, 1997.

FOUCAULT, M. Il faut defendre la société, Paris, Seuil, 1976.

FUGANTI, L. A. Saúde, desejo e pensamento, Saúde loucur, 2. São Paulo: Hucitec, 1990. 
HASHIZUME, C. M. Inclusão e Direitos Humanos: refletindo sobre o tema a partir da formação de professores. Contemporâneos. UFABC, ed. 19, mar. 2020 (no prelo).

HASHIZUME, C. M.; CARDOSO, M. T. CARDOSO, D. F. M. Medicalização na educação: uma reflexão sobre a medicalização de crianças e o papel do professor. Trabalho de Conclusão de curso. Pedagogia - São Bernardo do Campo-SP: UMESP, 2018.

HASHIZUME, C. M.; DIETRICH, A. M. (Orgs.). Direitos humanos no chão da escola: Um sonho possível. Santo André, SP, EDUFABC, 2017 (Coleção Transversalidades EDH).

HASHIZUME, C. M.; MOUTINHO, D. Medicalização na educação: refletindo sobre seus desdobramentos na saúde pública e direitos humanos. Cadernos de Educação: reflexão e debates, v. 17, n. 35, 2018.

HASHIZUME, C. M.; SANTOS, R. A. S. Medicalização no contexto escolar: estudo em São Bernardo do Campo (Projeto de Iniciação Científica). SB Campo: PPGE- UMESP, 2019.

INSFRAN, F. F. N. A formação de professores em um contexto neoliberal: como resistir? In: LEMOS, F. C. S. Conversas transversalizantes entre psicologia política, social-comunitária e institucional com os campos da educação, saúde e direitos, v. 7. Curitiba: CRV, 2017.

MACHADO, A. M. Reinventando a avaliação psicológica [tese]. São Paulo: Universidade de São Paulo, 1996.

MOYSÉS, Maria Aparecida Affonso. A medicalização na educação infantil e no ensino fundamental e as políticas de formação docente. Palestra proferida na $31^{\mathrm{a}}$. Reunião anual da Anped, 2008.S

MOYSÉS, Maria Aparecida Affonso; COLLARES, Cecília Azevedo Lima. Artigo Controle e medicalização da Infância. Temas em destaque, n. 1, ano 1, dez. 2013. Disponível em: <https://revistas.ufrj.br/index.php/desidades/article/viewFile/2456/2090>. Acesso em: 11/09/2018.

PATTO, M. H. S. Estado, ciência e política na Primeira República: a desqualificação dos pobres. Estud Av. São Paulo, 1999, 35 (13).

PIOVESAN, Flavia. Direitos sociais, econômicos e culturais e direitos civis e políticos. Sur, Rev. int. direitos human., São Paulo, v. 1, n. 1, p. 20-47, 2004. 
SCHWARCZ, L. M. O espetáculo das raças: cientistas, instituições e questão racial no Brasil (1870-1930). São Paulo: Companhia das Letras, 1993.

SECRETARIA MUNICIPAL DE SAÚDE, Protocolo de uso de Metilfenidato, Campinas, sem ano. Disponível em: <http://www.saude. campinas.sp.gov.br/assist_farmaceutica/Protocolo_Metilfenidato.pdf>. Acesso em: 08/10/2018.

SECRETARIADO MUNICIPAL DE SAÚDE, Recomendações do Mistério da Saúde para adoção de práticas não medicalizantes e para publicação de protocolos municipais e estaduais de dispensão de metilfenidato para prevenir a excessiva medicalização de crianças e adolescentes, Rio de Janeiro, 2015.

TEDESCO, S. T. \& NASCIMENTO, M. L. Ética e Subjetividade: novos impasses no contemporâneo. Porto Alegre: Sulina, 2009.

UDHR, Declaração Universal dos direitos humanos. Disponível em: < https://www.ohchr.org/EN/UDHR/Pages/Language.aspx?LangID=por $>$. Acesso em: $11 / 10 / 2018$.

ZUCOLOTO, Patrícia Carla Silva do Vale. O médico higienista na escola: as origens históricas da medicalização do fracasso escolar. Rev. bras. crescimento desenvolv. hum. [on-line], 2007, v. 17, n. 1. 